Neurosurg Focus 24 (1):E10, 2008

\title{
Perioperative challenges in the surgical management of ankylosing spondylitis
}

\author{
Daniel M. Sciubba, M.D., ${ }^{1}$ Clarke Nelson, B.S., ${ }^{1}$ Patrick Hsieh, M.D., ${ }^{1}$ \\ Ziya L. Gokaslan, M.D., ${ }^{1}$ Steve Ondra, M.D., ${ }^{2}$ AND Ali Bydon, M.D. ${ }^{1}$ \\ ${ }^{1}$ Department of Neurosurgery, Johns Hopkins University, Baltimore, Maryland;'2 \\ Department of Neurosurgery, Northwestern University, Chicago, Illinois
}

\begin{abstract}
$\checkmark$ Patients with ankylosing spondylitis (AS) who present with spinal lesions are at an increased risk for developing perioperative complications. Due to the rigid yet brittle nature of the ankylosed spines commonly occurring with severe spinal deformity, patients are more prone to developing neurological deficits. Such risks are potentially increased not only during surgical manipulation or deformity correction, but also during image acquisition, positioning within the operating room, and intubation. In this review the complications of AS are reviewed, and recommendations are provided to avoid problems during each stage of patient management. (DOI: 10.3171/FOC/2008/24/1/E10)
\end{abstract}

KEY WORDS • ankylosing spondylitis • perioperative complication • spine

A NKYLOSING spondylitis, a disease affecting $0.1-$ $0.5 \%$ of the population, is a chronic inflammatory spine disorder that presents significant challenges for the spine surgeon. ${ }^{7,12,15-19,34}$ Although the most common complaint of such patients is spreading lower back pain in $80-90 \%$ of clinical presentations, ${ }^{38}$ the majority of complaints are related to complications of spinal trauma or a progressive spinal deformity.

Patients with AS have a high preponderance of spinal instability because of increased rigidity across multiple spine segments in concert with osteopenia or osteoporosis. ${ }^{23}$ Autofusion across normally mobile segments leads to a spine that resembles a tubular long bone rather than a dynamic system of multiple parts. As a result, small forces acting along large long bone lever arms create greater rotational and translational strain, leading to greater risk of fracture displacement. ${ }^{29}$ Most frequently, patients present with fractures from the midcervical spine to the cervicothoracic junction (Fig. 1); ;,22 these patients are more likely to suffer severe neurological damage than patients with normal spines who present with fractures, reaching $75 \%$ with neurological damage in some series of cervical fractures. ${ }^{13,14,22,23}$ Although conservative treatment with a halothoracic plaster or jacket can be offered, such management can be associated with significant complications. ${ }^{38}$ As a result, many clinicians recommend early surgery, particularly in the case of spinal fractures.

\footnotetext{
Abbreviations used in this paper: AS = ankylosing spondylitis; $\mathrm{CT}=$ computed tomography; ICU = intensive care unit; $\mathrm{MR}=$ magnetic resonance; $\mathrm{MEP}=$ motor evoked potentials.
}

With regard to spinal deformity, reconstructive surgery in the spondylotic spine has the potential to cause severe neurological damage because of the complex dynamic forces involved in deformity correction acting on a both rigid and brittle spine. In addition, poor bone quality due to osteoporosis and osteopenia may lead to poor fixation and dislodgement of instrumentations, especially with the distinctive condition of the spine that acts more like a long, tubular bone structure than a system of articulating joints. ${ }^{29}$ Although surgery is commonly recommended for patients with AS who have spinal fractures or deformities, these patients pose several intraoperative challenges that may lead to significant complications and death if not recognized and efficiently managed. The surgeon must therefore be aware of several potential perioperative complications. In this review, imaging studies, intubation procedures, intraoperative positioning, and neurological monitoring will be discussed in relation to the patient with AS. Steps to avoid perioperative complications in these patients are provided in Table 1.

\section{Imaging Studies}

Imaging of the spine must be obtained prior to the initiation of any intervention in patients with AS who are suspected of having a spine lesion, particularly in a trauma setting. In addition, imaging studies must be acquired expeditiously due to the propensity for spinal instability in cases of traumatic injury, possibly leading to neurological decline.$^{45}$ Unfortunately the ability to conduct an accurate assessment of the spine is often restricted in these patients, 
TABLE 1

Steps for the avoidance of perioperative complications in patients with $A S^{*}$

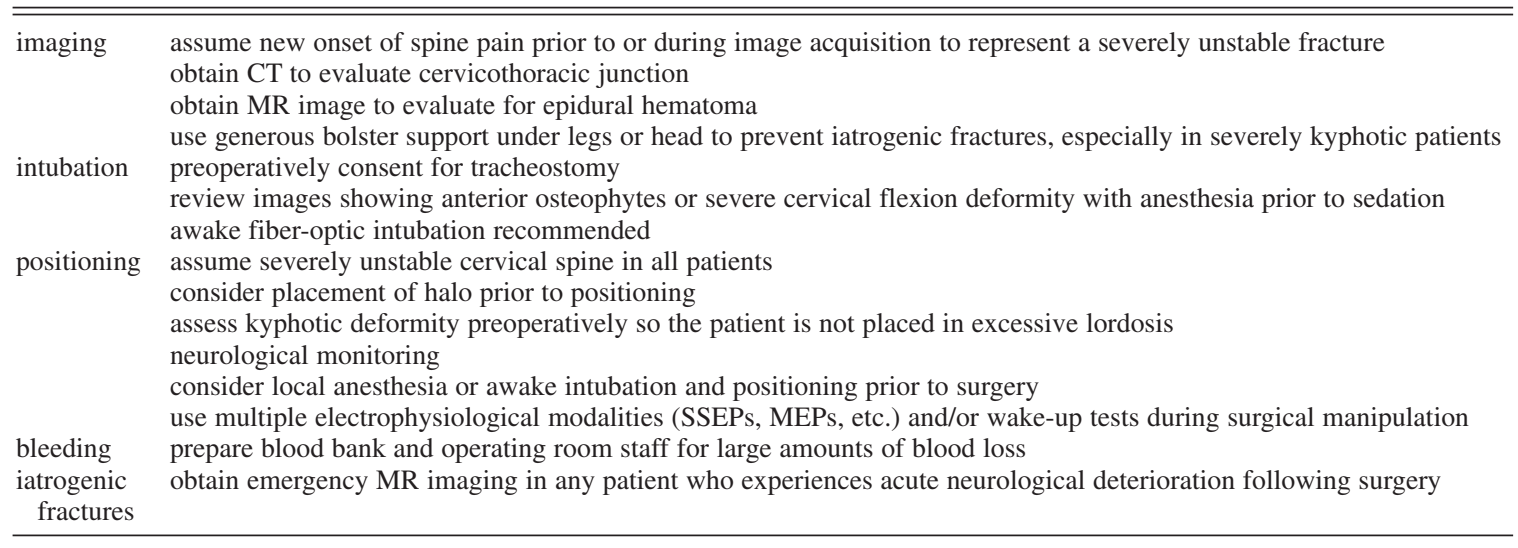

and additionally, the techniques required to obtain adequate images may place them at risk for additional injury. Further complicating the situation, frequently associated osteopenia may make the interpretation of radiographs difficult. Even with documented diagnosis of AS, the presence of cervicothoracic kyphosis may preclude adequate visualization and evaluation of the cervical spine on standard plain films. ${ }^{37}$ Meticulous review of imaging of the lower cervical

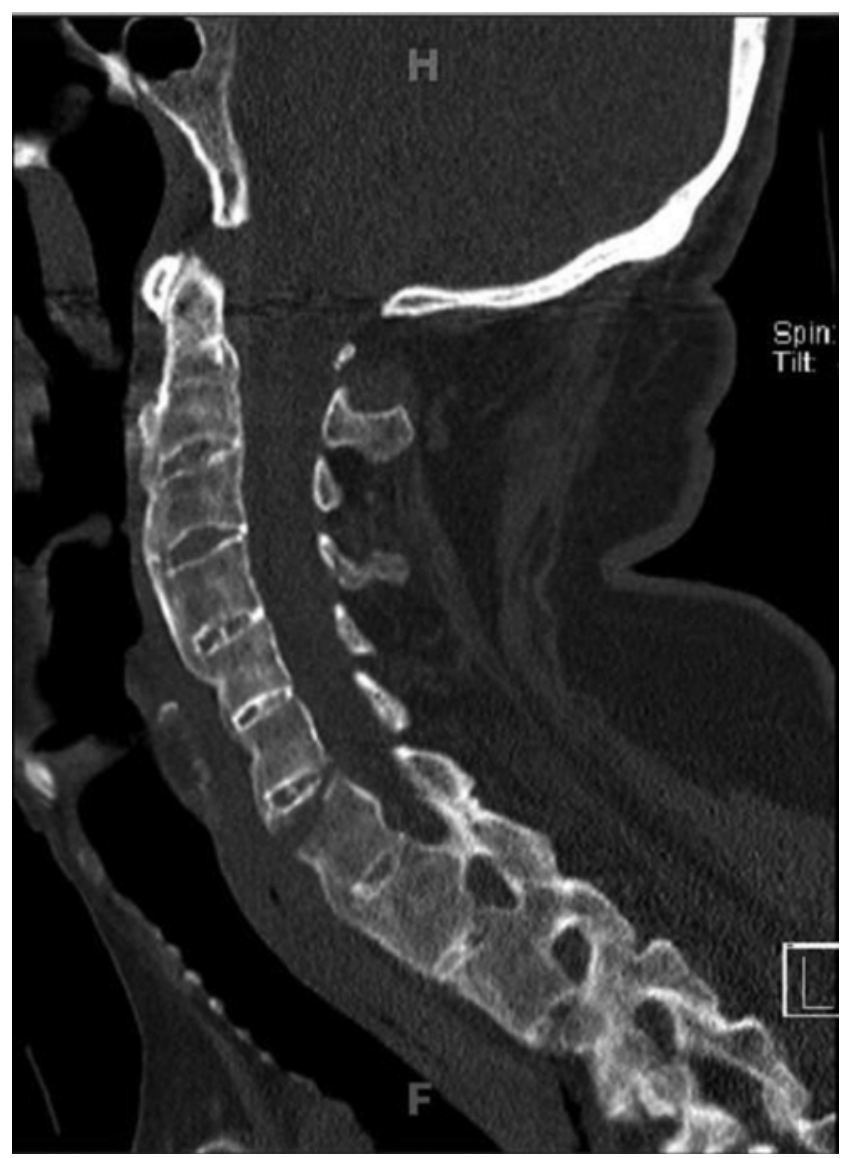

FIG. 1. Sagittally reconstructed image from a cervical spine CT scan, revealing a 3-column injury. and cervicothoracic junction is essential because the majority of fractures and deformities occur in this region in patients with AS. ${ }^{2}$

As a result of these difficulties, advanced imaging modalities such as CT and MR are invaluable adjuncts to plain films and fluoroscopy when obtaining images of the spine in patients with AS. The severe deformities in these patients often require special imaging reconstructions to allow the surgeon to properly visualize the spinal canal and other critical structures such as the vertebral pedicles at the apex of the deformity. Specifically, the ability to obtain 2D and 3D reconstructions in multiple anatomical planes on both CT and MR images allows physicians to assess spinal anatomy more accurately in patients with such complicated pathological entities. ${ }^{11,32,37}$ Magnetic resonance imaging is recommended for visualizing spinal cord and paraspinal soft tissue damage, and it is the recommended study to evaluate for the presence of an epidural hematoma, a lesion commonly found with fractures in patients with AS. ${ }^{3,432}$ If the supine position in intolerable because of pain or risk to neurological status, the right decubitus position is acceptable, or a pillow can be used to raise the pelvis and lower the head (Fig. 2). ${ }^{37}$

It must be kept in mind however that patients with AS frequently require additional care during positioning for advanced imaging studies, whether in the imaging suite or the operating room. Due to the frequency of fractures in the AS population, the clinician should assume any patient who reports insidious, radiating pain from the spine during image acquisition has suffered a fracture. Ruf et al. ${ }^{37}$ report-

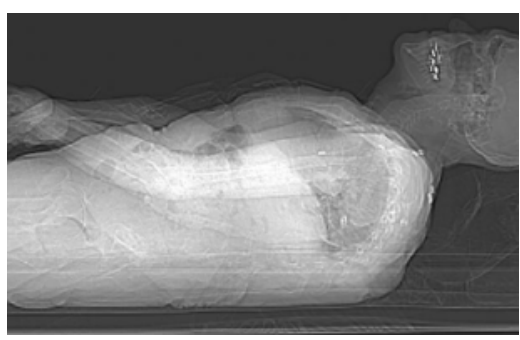

FIG. 2. Scout image obtained in CT scanner showing patient with severe upper thoracic kyphosis who could not lie comfortably in the scanner until large pillows were placed under his head. 


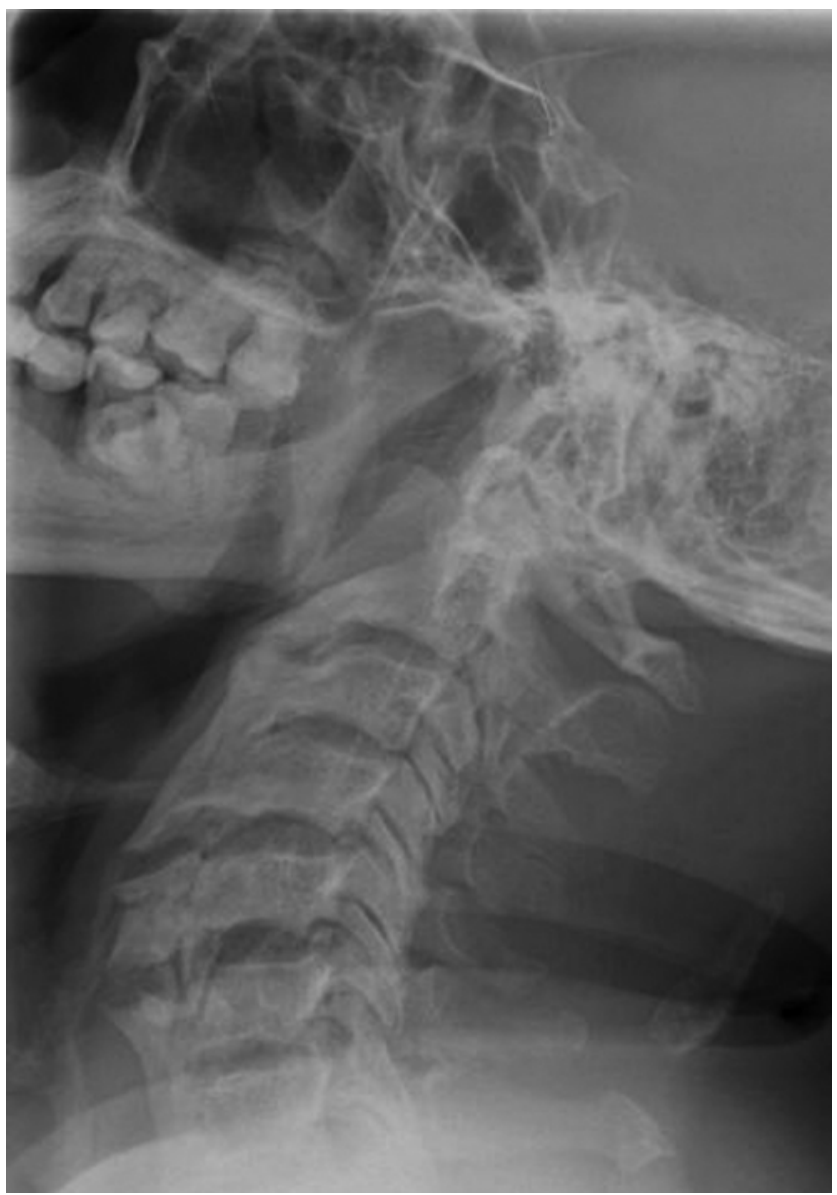

FIG. 3. Lateral radiograph obtained in a patient with AS showing anterior cervical osteophytes that may preclude successful endotracheal intubation.

ed on a case in which positioning a patient for plain radiography generated sufficient pressure on the spinal column to fracture L-3. In patients with kyphotic deformities, generous use of bolsters and padding should be used to relieve stress on the hips and thorax. ${ }^{43}$ Prolonged pressure on those areas may place significant strain on the intervening brittle spine, in some cases leading to a fracture.

\section{Intubation}

Although a smooth and successful intubation is of paramount importance in airway management and prior to any surgical intervention, the risks are significantly increased in patients with AS. First, the presence of large anterior cervical osteophytes may prohibit successful visualization of the larynx and may prevent endotracheal intubation due to significant mass obstruction. In Fig. 3, a lateral radiograph is shown that was obtained in a patient who presented with disphagia presumably caused by distortion of soft tissues from bone overgrowth. The patient underwent successful intubation followed by drilling of the anterior osteophytes. Cesur et al. ${ }^{8}$ reported on a case in which an osteophyte prevented numerous attempts at intubation. After the patient was placed under general anesthesia, the anesthesiologist attempted several endotracheal intubations without suc-

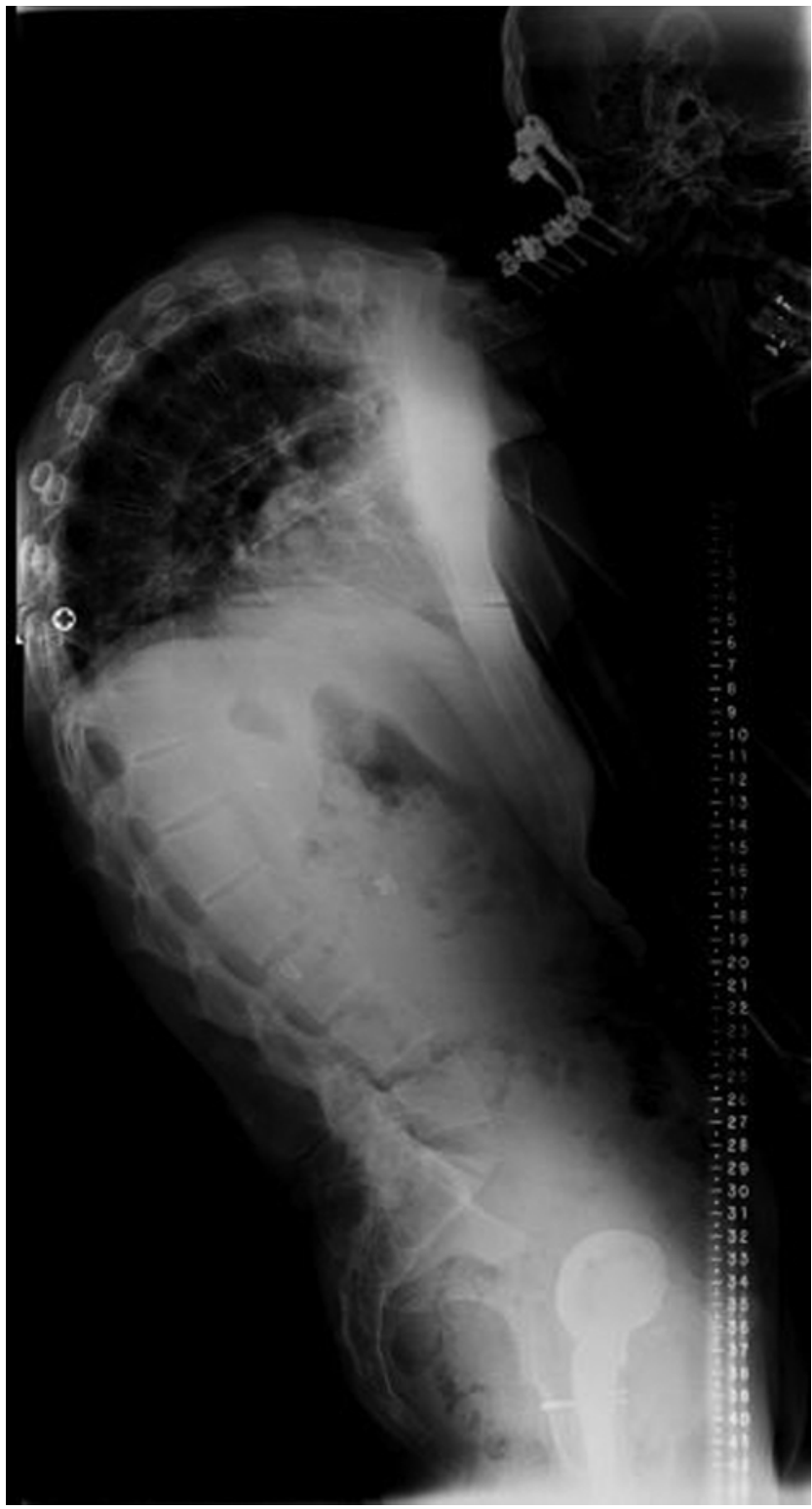

FIG. 4. Lateral radiograph obtained in a patient with AS. Severe cervical flexion deformity, a condition that may preclude successful endotracheal intubation, is demonstrated.

cess. Successive attempts included blind nasotracheal intubation, placement of a laryngeal mask airway, and retrograde intubation, but all were unsuccessful. Using Magill forceps during direct laryngoscopy, intubation was finally achieved. The authors recommend that radiological studies be conducted prior to intubation of any patient with AS so that the presence of obstructive entities can be determined. Although osteophytes large enough to obstruct the airway significantly are not exceedingly common, ${ }^{8,36}$ standard manipulation of the neck during endotracheal intubation may be complicated by the weak and brittle nature of cervical spine. Therefore, relatively minor flexion or extension forces during head positioning for intubation could lead to the creation of iatrogenic fractures by the intubation professional. ${ }^{35}$ 


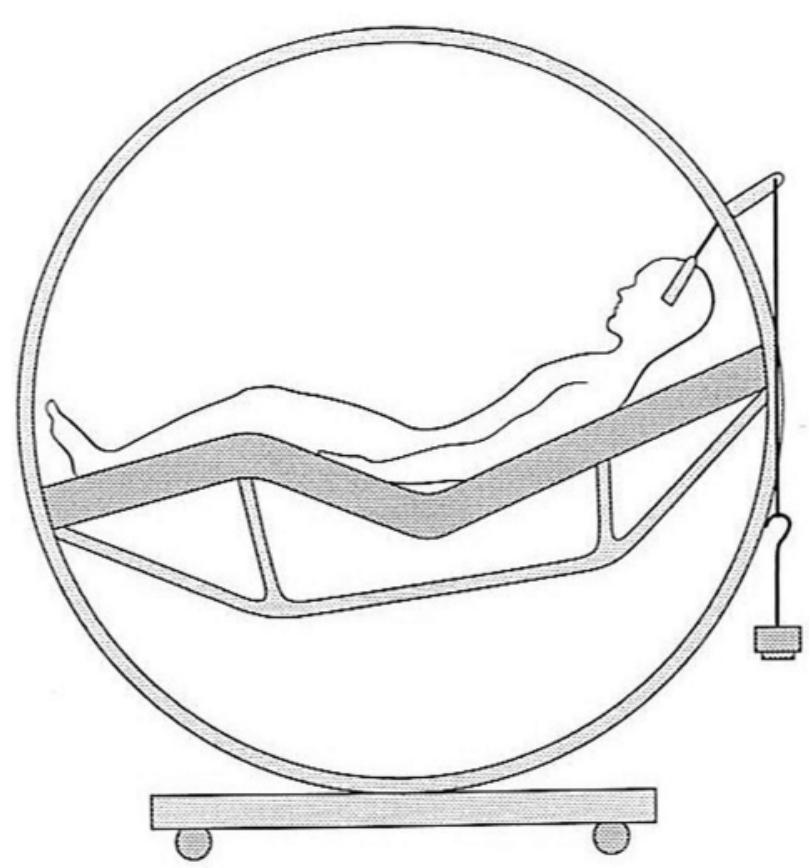

FIG. 5. Schematic of the circle electric bed. Note how the patient's position may be changed without altering the orientation of the head relative to the torso. Published with permission of Lippincott (from Clark CR et al.: The Cervical Spine, ed 4. Philadelphia: Lippincott Williams \& Wilkins).

Cervical flexion deformity, also known as chin-on-chest deformity, may also contribute significant challenges during intubation. When preoperative assessments show limited ability to open the mouth or move the neck, options for intubation are reduced (Fig. 4). Simmons and colleagues ${ }^{40}$ reported success using local anesthesia for reduction of such deformities via cervical opening wedge osteotomies with the patient in the sitting position (a technique pioneered by Urist in $1958^{46}$ ). Since their study, however, advances in intubation, positioning, airway monitoring, and neurological monitoring have improved and now allow surgeons to perform operations in patients under general anesthesia in the prone position. Currently, patients with these deformities can be successfully treated with nasotracheal fiberoptic intubation if attempts with other techniques have failed..$^{26,44}$ As a special consideration for patients with AS, informed consent should include obtaining a consent for tracheotomy in the event that an obstructive cervical osteophyte or severe cervical flexion deformity prevent successful intubation. ${ }^{8}$

\section{Patient Positioning}

Proper positioning of a patient with AS in the operating room or the ICU is imperative not only for the patient with an unstable fracture, but in all AS patients because of their an increased risk of iatrogenic injury. During head positioning, the surgeon must take into account the sagittal alignment of the cervical spine, which may often be significantly kyphotic. When fractures already exist in these patients, inadequate assessment of the mass of the head and the extent of cervical kyphosis can have disastrous effects such as complete spinal cord damage and possible death. Hunter and colleagues ${ }^{22}$ reported on a case in which rotating a patient in traction led to death.

In surgeries involving osteotomy or reduction of the cervical spine, preoperative halo placement and traction have shown success in improving stability during positioning. 2,10,31,40,45 To allow a certain degree of freedom for patients with AS in the operating room or ICU, a number of adaptations to patient beds have been developed to accommodate prolonged immobilization. Such advances have particular relevance for the AS population because they allow the patient to maintain a more comfortable kyphotic condition with cervical traction. For instance, the circle electric bed may allow movement that would otherwise be contraindicated because of associated alteration of traction. ${ }^{11}$ This apparatus allows the patient to be rotated within a circular frame with a fixed head position relative to the torso throughout all maneuvers, such that sagittal alignment and traction are maintained. Postoperatively, specialized beds such as these also facilitate changing from a supine or prone position to an upright position. ${ }^{40}$ When using such beds, it has been recommended that only enough traction to counterbalance the head be used. ${ }^{11,40}$ At our institutions, patients with cervical flexion deformity are placed in a Mayfield head frame to minimize excessive movement of the head relative to the torso. Such rigid stabilization also serves to elevate the patient's face from the operative bed, eliminating prolonged contact with underlying cushions. This maneuver, combined with a reverse Trendelenburg position, may serve to decrease intraocular pressure and ocular venous pressure, which may potentially decrease the incidence of postoperative blindness.

\section{Neurological Monitoring}

The ability to monitor the neurological status of any patient during positioning or surgical manipulation is extremely important in any spine surgery. However, due to the significant spinal instability in patients with AS and the potential serious complications associated with surgical manipulation, neurological monitoring in such patients is critical. The Scoliosis Research Society in $1974^{41}$ found that aggressive surgeries to correct deformities were associated with severe postoperative neurological deficits, and thus the society advised the universal use of intraoperative monitoring. In patients with AS, this statement is especially relevant. The surgeon must first decide whether the patient should receive general anesthesia at all. Because of the potentially hazardous nature of osteotomy procedures, a local anesthetic can be administered for frequent neurological assessments during deformity correction. Urist ${ }^{46}$ was one of the first to report success with cervical osteotomy with the patient in the sitting position and with local anesthesia. Such operations carry a high risk of neurological complications due to the potential for iatrogenic cervical subluxation and spinal cord compromise, and thus continual feedback on neurological status provided by the awake patient is especially important. ${ }^{1,10,29}$ Nevertheless, performing these complex corrective spinal procedures on awake patients is a challenging task and is done on a rare basis.

Many complex spine surgeries however, require patients 
to be in the prone position for prolonged periods with extensive soft tissue exposure, making awake surgeries uncomfortable or completely infeasible for the patient. For this reason, the wake-up test, a technique originally introduced by Vazuelle and Stagnara in $1973,{ }^{47}$ has been used to monitor the neurological status of patients undergoing prolonged spine deformity surgeries in the prone position. Specifically, after surgical manipulation of the spine, the level of sedation is reduced and the patient is asked to squeeze the hand of the anesthesiologist or move his lower extremities. Currently, placement of the patient in the prone position under general anesthesia is the preferred method for most spine surgeries, including those in patients with AS because it allows the surgeon easier access and manipulations of the spine, and the patient can tolerate a longer procedure..$^{5,6,920,21,27}$ In addition, in patients in whom osteotomies are needed in the thoracic or lumbar spine, a large surgical exposure necessitates the the use of the prone position with general anesthesia.

Some surgeons feel that the cervical spine region is at a particularly high risk for neurovascular complications compared with the lumbar or thoracic area due to the higher level of the associated spine cord and accompanying vertebral arteries. ${ }^{40}$ The unique challenges inherent to cervical osteotomy procedures led Urist ${ }^{40}$ and Simmons et al. ${ }^{46}$ to recommend the use of a local anesthetic in AS deformity correction procedures to permit multiple real-time neurological examinations. These patients, however, are at severe risk of neurological damage should they suddenly move their spines in their sedated and disoriented state. ${ }^{10}$ For this reason Law et al. ${ }^{28}$ were the first to report successful reduction of a severe cervical flexion deformity with general anesthesia in the prone position. Since their study, authors such as Chin and associates ${ }^{10}$ have conducted cervical osteotomies in patients using a Jackson table while monitoring neurological status using neurophysiological techniques.

Along these lines, if the decision has been made to proceed using general anesthesia, with or without the use of wake-up tests, many authors have stated that neurolophysiological monitoring is absolutely required. ${ }^{10,27,28,33,39-41}$ Common techniques include spinal cord evoked potentials introduced by Tamaki and Yamane ${ }^{42}$ and Kurokawa, ${ }^{25}$ somatosensory cortical evoked potentials introduced by Nash and Brown, ${ }^{33}$ spinal somatosensory evoked potentials introduced by Shimoji et al., ${ }^{39}$ and muscle MEPs introduced by Merton and Morton. ${ }^{30}$ Unfortunately, such studies may not be sensitive enough to reliably predict neurological damage. ${ }^{41}$ For instance, Bridwell et al. ${ }^{5}$ described a series of 33 patients among whom 5 suffered neurological deficits not predicted on somatosensory cortical evoked potentials or MEPs. In 2 patients, the deficits were diagnosed via Stagnara wake-up tests. Conversely, Langeloo et al. ${ }^{27}$ reported success in detecting neurological decline using transcranial electrical stimulated-MEPs, with early recognition of 9 events, 8 of which were corrected. Because there may exist discrepancies in sensitivity among the various monitoring techniques, it is now recommended that multiple and continuous neurological monitoring methods be used in addition to wake-up tests so that any false negatives provided by the electrophysiological recording are eliminated. ${ }^{10,41}$

\section{Intraoperative Blood Loss}

Operations involving patients with AS have been associated with increased perioperative blood loss..$^{25,33,44}$ In some patients with kyphotic deformities, the presence of a highly curved spine prohibits achievement of a free-hanging abdomen. Specifically, if the abdomen is not supported, there is increased pressure applied to the chest with resultant increases in peak inspiratory pressure and ventilation problems. To compensate, generous additional padding may be used to relieve the pressure at the cost of increasing abdominal pressure and causing a resultant increase in central venous pressure, leading to distention of the epidural venous plexus. Tetzlaff and colleagues ${ }^{43}$ described a procedure involving a patient undergoing decompression, osteotomy, and fusion at T-12 with blood loss of 17,000 ml perioperatively. Blood-loss issues can further be complicated by the inability to visualize the accumulation of an epidural hematoma on radiography or CT scans. Magnetic resonance imaging is considered the imaging modality of choice by radiologists for the diagnosis of hemorrhaging in such cases. . $^{32,37}$

\section{Iatrogenic Fractures}

Due to severe spinal rigidity in patients with $\mathrm{AS}$, deformity correction relies largely on the use of vertebral osteotomy procedures. Unfortunately, the lack of supporting ligamentous structures around the spine in these patients can make controlled fractures unpredictable and dangerous. Moreover, the long levers created by ankylosed vertebrae can generate significant translational and rotational forces that may lead to unintended subluxation of the spine leading to spinal cord compression. Belanger et al. ${ }^{1}$ reported on a case in which the patient experienced quadriplegia immediately following a cervical osteotomy procedure performed with the patient under local anesthesia and in the sitting position. The patient eventually died in the ICU of pneumonia and heart failure. Radiographs obtained in the patient demonstrated a subluxation at the site of the osteotomy.

In addition to problems at the surgical site, unintended fractures can arise at sites distant to the segments that are undergoing surgical manipulation. Ruf et al. ${ }^{37}$ reported on 2 such cases. One patient developed acute quadriplegia 15 hours after undergoing surgical correction of C1-2 anterolisthesis. Emergency MR imaging showed a hyperextension-type fracture through C6-7 with stenosis via the C-6 lamina and spinal cord edema. In addition a cerebral infarction resulted from blockage of the right vertebral artery, and the patient eventually died of stroke complications. The second patient in their study underwent a wedge osteotomy at T8-9 with cage interposition and T4-L1 posterior instrumentation for treatment of thoracic hyperkyphosis. Soon after the surgery, the patient was found to have an alarming level of mobility in the cervical spine. Emergency MR imaging with the patient still under anesthesia revealed a hyperextension rupture of the C6-7 intervertebral disc; a segmental lordosis of $10^{\circ}$ was noted, as well as a small hematoma within the epidural space at T6-7. For such reasons, an extremely focused physical examination should be conducted after such procedures. 


\section{Conclusions}

The severely rigid yet brittle nature of the spine in patients with AS must not be underestimated when managing their care in the emergency room, operating room, or ICU. An increased rate of neurological damage exists in these patients due to excessive rotation and angulation at fracture sites, a phenomenon exacerbated by preexisting deformity and associated corrective maneuvers. Thus the routine management of patients with spinal lesions, including effective imaging, intubation, positioning, neurological monitoring, and deformity correction becomes particularly challenging in patients with AS. Early recognition of potential pitfalls and complications associated with the treatment of patients with AS will help to avoid preventable or iatrogenic injuries.

\section{References}

1. Belanger TA, Milam RA IV, Roh JS, Bohlman HH: Cervicothoracic extension osteotomy for chin-on-chest deformity in ankylosing spondylitis. J Bone Joint Surg Am 87:1732-1738, 2005

2. Benzel EC (ed): Spine Surgery: Techniques, Complication Avoidance, and Management, ed 2. Philadelphia: Churchill Livingston, 2005, Vol 1

3. Braun J, Golder W, Bollow M, Sieper J, van der Heijde D: Imaging and scoring in ankylosing spondylitis. Clin Exp Rheumatol 20 (6 Suppl): S178-S184, 2002

4. Braun J, Rudwaleit M, Hermann KG, Rau R: [Imaging in ankylosing spondylitis.] Z Rheumatol 66:167-178, 2007 (Ger)

5. Bridwell KH, Lewis SJ, Edwards C, Lenke LG, Iffrig TM, Berra A, et al: Complications and outcomes of pedicle subtraction osteotomies for fixed sagittal imbalance. Spine 28:2093-2101, 2003

6. Bridwell KH, Lewis SJ, Rinella A, Lenke LG, Baldus C, Blanke $\mathrm{K}$ : Pedicle subtraction osteotomy for the treatment of fixed sagittal imbalance. Surgical technique. J Bone Joint Surg Am 86 (1 Suppl):44-50, 2004

7. Cardenosa G, DeLuca SA: Ankylosing spondylitis. Am Fam Physician 42:147-150, 1990

8. Cesur M, Alici HA, Erdem AF: An unusual cause of difficult intubation in a patient with a large cervical anterior osteophyte: a case report. Acta Anaesthesiol Scand 49:264-266, 2005

9. Chang KW: Oligosegmental correction of post-traumatic thoracolumbar angular kyphosis. Spine 18:1909-1915, 1993

10. Chin KR, Ahn J: Controlled cervical extension osteotomy for ankylosing spondylitis utilizing the Jackson operating table: technical note. Spine 32:1926-1929, 2007

11. Clark CR (ed): The Cervical Spine. Philadelphia: Lippincott Williams \& Wilkins, 2005, Vol 1

12. Einsiedel T, Schmelz A, Arand M, Wilke HJ, Gebhard F, Hartwig $\mathrm{E}$, et al: Injuries of the cervical spine in patients with ankylosing spondylitis: experience at two trauma centers. J Neurosurg Spine 5:33-45, 2006

13. Graham B, Van Peteghem PK: Fractures of the spine in ankylosing spondylitis. Diagnosis, treatment, and complications. Spine 14:803-807, 1989

14. Graham GP, Evans PD: Spinal fractures in patients with ankylosing spondylitis. Injury 22:426-427, 1991

15. Gran JT: An epidemiological survey of the signs and symptoms of ankylosing spondylitis. Clin Rheumatol 4:161-169, 1985

16. Gran JT, Husby G: Ankylosing spondylitis: a comparative study of patients in an epidemiological survey, and those admitted to a department of rheumatology. J Rheumatol 11:788-793, 1984

17. Gran JT, Husby G: Clinical, epidemiologic, and therapeutic aspects of ankylosing spondylitis. Curr Opin Rheumatol 10: 292-298, 1998
18. Gran JT, Husby G: The epidemiology of ankylosing spondylitis. Semin Arthritis Rheum 22:319-334, 1993

19. Gran JT, Husby G: On the prevalence of ankylosing spondylitis. J Rheumatol 14:174-175, 1987

20. Hitchon PW, From AM, Brenton MD, Glaser JA, Torner JC: Fractures of the thoracolumbar spine complicating ankylosing spondylitis. J Neurosurg 97:218-222, 2002

21. Hitchon PW, Torner J, Eichholz KM, Beeler SN: Comparison of anterolateral and posterior approaches in the management of thoracolumbar burst fractures. J Neurosurg Spine 5:117-125, 2006

22. Hunter T, Dubo H: Spinal fractures complicating ankylosing spondylitis. Ann Intern Med 88:546-549, 1978

23. Hunter T, Forster B, Dvorak M: Ankylosed spines are prone to fracture. Can Fam Physician 41:1213-1216, 1995

24. Hyderally HA: Epidural hematoma unrelated to combined spinalepidural anesthesia in a patient with ankylosing spondylitis receiving aspirin after total hip replacement. Anesth Analg 100: 882-883, 2005

25. Kurokawa T: [Electrospinogram (author's transl).] No To Shinkei 30:467-484, 1978

26. Lai HY, Chen IH, Chen A, Hwang FY, Lee Y: The use of the GlideScope for tracheal intubation in patients with ankylosing spondylitis. Br J Anaesth 97:419-422, 2006

27. Langeloo DD, Journee HL, Pavlov PW, de Kleuver M: Cervical osteotomy in ankylosing spondylitis: evaluation of new developments. Eur Spine J 15:493-500, 2006

28. Law WA: Osteotomy of the cervical spine. J Bone Joint Surg Br 41:640-641, 1959

29. Mason C, Cozen L, Adelstein L: Surgical correction of flexion deformity of the cervical spine. Calif Med 79:244-246, 1953

30. Merton PA, Morton HB: Stimulation of the cerebral cortex in the intact human subject. Nature 285:227, 1980

31. Murray GC, Persellin RH: Cervical fracture complicating ankylosing spondylitis: a report of eight cases and review of the literature. Am J Med 70:1033-1041, 1981

32. Nakstad PH, Server A, Josefsen R: Traumatic cervical injuries in ankylosing spondylitis. Acta Radiol 45:222-226, 2004

33. Nash CL Jr, Brown RH: The intraoperative monitoring of spinal cord function: its growth and current status. Orthop Clin North Am 10:919-926, 1979

34. Palm O, Moum B, Ongre A, Gran JT: Prevalence of ankylosing spondylitis and other spondyloarthropathies among patients with inflammatory bowel disease: a population study (the IBSEN study). J Rheumatol 29:511-515, 2002

35. Palmer AR: Tracheal intubation and cervical injury. Can J Anaesth 40:470-471, 1993

36. Ranasinghe DN, Calder I: Large cervical osteophyte-another cause of difficult flexible fiberoptic intubation. Anaesthesia 49: 512-514, 1994

37. Ruf M, Rehm S, Poeckler-Schoeniger C, Merk HR, Harms J: Iatrogenic fractures in ankylosing spondylitis - a report of two cases. Eur Spine J 15:100-104, 2006

38. Schroder J, Liljenqvist U, Greiner C, Wassmann H: Complications of halo treatment for cervical spine injuries in patients with ankylosing spondylitis-report of three cases. Arch Orthop Trauma Surg 123:112-114, 2003

39. Shimoji K, Higashi H, Kano T: Epidural recording of spinal electrogram in man. Electroencephalogr Clin Neurophysiol 30: 236-239, 1971

40. Simmons ED, DiStefano RJ, Zheng Y, Simmons EH: Thirty-six years experience of cervical extension osteotomy in ankylosing spondylitis: techniques and outcomes. Spine 31:3006-3012, 2006

41. Tamaki T, Kubota S: History of the development of intraoperative spinal cord monitoring. Eur Spine J, 2007

42. Tamaki T, Yamane T: Proceedings: Clinical utilization of the evoked spinal cord action potential in spine and spinal cord surgery. Electroencephalogr Clin Neurophysiol 39:539, 1975

43. Tetzlaff JE, Yoon HJ, Bell G: Massive bleeding during spine sur- 
Perioperative challenges in the surgical management of ankylosing spondylitis

gery in a patient with ankylosing spondylitis. Can J Anaesth 45:903-906, 1998

44. Uakritdathikarn T: Lightwand-assisted nasotracheal intubation in awake ankylosing spondylitis. J Med Assoc Thai 89:1976-1980, 2006

45. Upadhyay SS, Ho EK, Hsu LC: Positioning for plain spinal radiography producing paraplegia in a patient with ankylosing spondylitis. Br J Radiol 64:549-551, 1991

46. Urist MR: Osteotomy of the cervical spine; report of a case of ankylosing rheumatoid spondylitis. J Bone Joint Surg Am 40: 833-843, 1958
47. Vauzelle C, Stagnara P, Jouvinroux P: Functional monitoring of spinal cord activity during spinal surgery. Clin Orthop Relat Res 93:173-178, 1973

Manuscript submitted October 24, 2007.

Accepted November 8, 2007.

Address correspondence to: Daniel M. Sciubba, M.D., 600 North Wolfe Street Meyer Building 8-161, Baltimore, Maryland 21237. email: dsciubb1@jhmi.edu. 